\title{
Rapid and sensitive detection of Escherichia coli 0157:H7 using coaxial channel-based DNA extraction and microfluidic PCR
}

\author{
Huilin Zhang, ${ }^{*}$ Fengchun Huang, ${ }^{*}$ Gaozhe Cai, ${ }^{*}$ Yuntao Li, $\dagger$ and Jianhan Lin* ${ }^{1}$ \\ *Key Laboratory of Agricultural Information Acquisition Technology, Ministry of Agriculture, China Agricultural University, Beijing 100083, China \\ †State Key Lab of Integrated Optoelectronics, Institute of Semiconductors, Chinese Academy of Science, Beijing 100083, China \\ łKey Laboratory of Modern Precision Agriculture System Integration Research, Ministry of Education, China Agricultural University, \\ Beijing 100083, China
}

\begin{abstract}
In this study, a rapid and sensitive method for detection of Escherichia coli O157:H7 using the coaxial channel-based DNA extraction and the microfluidic PCR was proposed and verified. The magnetic silica beads were first pumped into the coaxial channel, which was captured in the coaxial channel more uniformly by applying the multiring high-gradient magnetic field. After the E. coli O157:H7 cells were lysed with the lysis buffer to release the DNA, the improved coaxial channel was used to efficiently extract the DNA, followed by washing with ethanol to remove the residual proteins and eluting with a small volume of deionized water to obtain the purified and concentrated DNA. Finally, the obtained DNA was amplified and determined using the microfluidic PCR. This proposed bacteria detection method was able to detect $E$. coli $\mathrm{O} 157: \mathrm{H} 7$ as low as $12 \mathrm{cfu} / \mathrm{mL}$ when the large volume $(10 \mathrm{~mL})$ of bacterial sample was used, and the recovery of E. coli O157:H7 in the spiked milk samples ranged from 97.4 to $100.6 \%$. This proposed bacteria detection method has shown great potential to detect lower concentration of $E$. coli O157:H7 from larger volumes of sample.
\end{abstract}

Key words: DNA extraction, coaxial channel, microfluidic PCR, large volume

\section{INTRODUCTION}

Recently, outbreaks of food-borne diseases due to contamination with pathogenic bacteria have resulted in tremendous economic losses and posed great threats to human health. A key to ensure food safety is rapid screening of contaminated foods. However, the gold standard method for bacteria detection, culture plating, is time-consuming and cannot be used for applications in the field (Pandey et al., 2017). Therefore, it is

Received March 11, 2018.

Accepted July 21, 2018.

${ }^{1}$ Corresponding author: jianhan@cau.edu.cn crucial to develop rapid and sensitive methods to detect the pathogenic food-borne bacteria.

Polymerase chain reaction is a rapid, sensitive and high-throughput method and has been widely used for fast detection of food-borne bacteria. The procedure for PCR detection of food-borne bacteria mainly includes nucleic acid extraction, amplification, and detection. Currently, different PCR methods, including conventional PCR (Chandrashekhar et al., 2015), real-time PCR (Chen et al., 2010; Lee et al., 2010), multiplex PCR (Kérouanton et al., 2010; Ali et al., 2014; Sheng et al., 2018), immune PCR (Abolmaaty et al., 2013; Ryazantsev et al., 2016), and microfluidic PCR (Bian et al., 2015; Ganesh et al., 2016), have been reported for the detection of various bacteria. With the fast development of microfluidics, microfluidic PCR is receiving more and more attention due to its shorter detection time, automatic operation, less cross-contamination, and lower cost (Zhang and Jiang, 2016). However, less attention has been paid to the extraction of nucleic acids from complex food samples, which is the essential precondition for PCR detection and has great effect on sensitivity and specificity.

The conventional methods for nucleic acid extraction mainly include cetyltrimethylammonium bromide method, alkaline method, and phenol-chloroform method, which are often complex, labor-intensive and time-consuming with unsatisfactory reproducibility and toxic reagents (Casey and McAuliffe, 2014; Stefanova et al., 2014; Yalçinkaya et al., 2017). More importantly, they are not suitable for extracting a small amount of target DNA from a large volume of samples. In the past decades, magnetic silica beads (MSB) have often been reported for rapid extraction of DNA (Levison et al., 1998; Jie et al., 2012; Bai et al., 2013). Briefly, the bacterial sample is first lysed with the lysis buffer containing protease $\mathrm{K}$ to release the DNA. The MSB are then used to capture the DNA through electrovalent binding, electrostatic interaction, or hydrophobic interaction. After washing with ethanol to remove surplus proteins and polysaccharides, the DNA is eluted from 
the MSB using a small volume of elution buffer (such as deionized water), and the purified and concentrated DNA can be obtained after magnetic separation.

Recently, microfluidic devices with different MSB have been reported for DNA extraction and shown potential to provide automatic solutions to extract the target DNA in a centimeter-level chip (Mauk et al., 2015). These devices featured shorter extraction time, less reagent consumption, and simpler operation, but often had low sensitivity because they could only handle a very small volume of sample (microliter level, even nanoliter level). Gan et al. (2017) reported a chitosan-modified filter paper for extraction and concentration of the standard K562 human genomic DNA and bacteriophage $\lambda$-DNA, which was used with situ PCR on a thermoplastic microchip by using the physical entanglement of long-chain DNA with the fiber matrix of the paper and the electrostatic adsorption of DNA to the chitosan-modified fibers. The DNA capture efficiency was up to $95 \%$; however, it was not suitable for DNA extraction from a large volume of sample. Consequently, new methods using immiscible filtration assisted by surface tension were reported for the purification of nucleic acids (Berry et al., 2011; Bordelon et al., 2011). Sur et al. (2010) used a single pass of paramagnetic particles with nucleic acids from the lysis buffer through an immiscible hydrophobic liquid (wax) to the elution buffer in the cartridge. The yielded nucleic acids were as pure as that obtained with conventional purification methods. Bordelon et al. (2013) developed a magnetic silica bead-based method for extracting and concentrating the synthetic DNA target from the IS6110 sequence of Mycobacterium tuberculosis from 1 $\mathrm{mL}$ of human urine with 60 -cm-long tubing over $15 \mathrm{~min}$ and obtained a low detection limit of 77 copies $/ \mathrm{mL}$ for the urine sample. This is a promising method for extracting DNA from a large volume of sample.

In our previous studies, we developed 2 coaxial channels for the immunomagnetic separation of foodborne bacteria (Wang et al., 2017; Huang et al., 2018); however, some limitations existed, such as nonuniform distribution of the magnetic field or inability to release the magnetic nanobeads. Moreover, the methods required more incubation time to achieve sufficient immunoreaction between the antibodies and the antigens at the specific binding sites. However, the adsorption of nucleic acids by the MSB theoretically needs less time, as nucleic acids can be conjugated with the MSB in all directions due to electrostatic interaction, indicating that this coaxial channel might be easier for DNA extraction than immune magnetic separation. Therefore, the current study intended to develop a rapid and sensitive method for the detection of E. coli O157:H7 using the improved coaxial channel for DNA extraction and the microfluidic PCR for DNA amplification and detection.

\section{MATERIALS AND METHODS}

\section{Materials}

Phosphate buffered saline (10 $\mathrm{m} M, \mathrm{pH}$ 7.4) was obtained from Sigma-Aldrich (St. Louis, MO). Bovine serum albumin from EM Science (Gibbstown, NJ) was prepared in PBS $(1.0 \%$, wt/vol) and used for blocking. Absolute ethanol from Sinopharm (Beijing, China) was used for washing. The magnetic silica beads with the diameter of $\sim 1 \mu \mathrm{m}$ from Huier Nano (Cat\#: HRXJ0030, Luoyang, Henan, China) were used to capture the DNA. The nucleic acid detection kit from Mabsky Biotech (Cat\#: SKY-8128, Shenzhen, Guangdong, China) was used for PCR detection of E. coli O157:H7. The deionized water produced by Millipore Advantage 10 (18.2 $\mathrm{M} \Omega \cdot \mathrm{cm}$, Billerica, MA) was used for eluting the DNA and preparing all the solutions.

\section{Preparation of the Bacteria Culture}

For the pure cultures, E. coli O157:H7 (ATCC43888, used as the target bacteria) stored with $15 \%$ glycerol at $-20^{\circ} \mathrm{C}$ were revived by streaking on Luria-Bertani agar plates. They were cultured at $37^{\circ} \mathrm{C}$ at $180 \mathrm{rpm}$ for 12 to $14 \mathrm{~h}$ with an estimated concentration of $\sim 10^{9} \mathrm{cfu} / \mathrm{mL}$, and then serially 10 -fold diluted with the sterile PBS to prepare the pure bacteria cultures with the concentrations of $10^{1}$ to $10^{9} \mathrm{cfu} / \mathrm{mL}$.

For bacterial enumeration, the bacterial samples were serially 10 -fold diluted with the sterile PBS, and $100 \mu \mathrm{L}$ of the diluents were surface plated on the LuriaBertani agar plates. The plates were incubated at $37^{\circ} \mathrm{C}$ for 22 to $24 \mathrm{~h}$ and the visible colonies were counted for enumeration of the bacteria.

\section{Improvement of the Coaxial Channel}

The DNA extraction method was dependent on the binding of the magnetic silica beads and the target DNA in the coaxial channel. Similar to our previous design (Wang et al., 2017; Huang et al., 2018), the coaxial channel consisted of an inner quartz capillary (inner diameter $=1.0 \mathrm{~mm}$, outer diameter $=1.2 \mathrm{~mm})$ and an outer quartz capillary (inner diameter $=1.8 \mathrm{~mm}$, outer diameter $=2.0 \mathrm{~mm}$ ). As shown in Figure 1, the inner capillary was filled with an iron ball chain with the diameter of $0.8 \mathrm{~mm}$, and both ends of the capillary were connected with 2 cylinder aligners, which were 
(a)
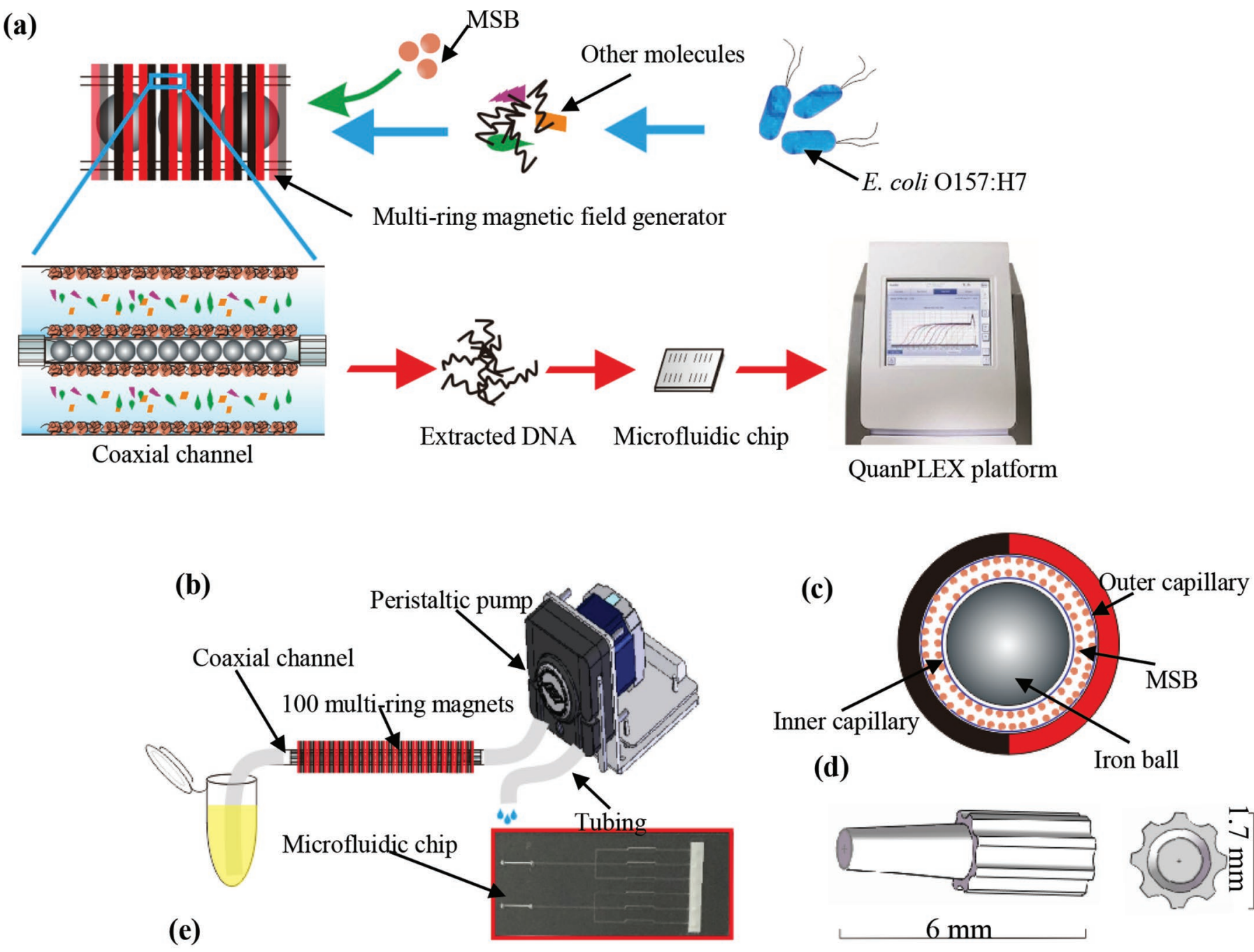

(d)

Iron ball
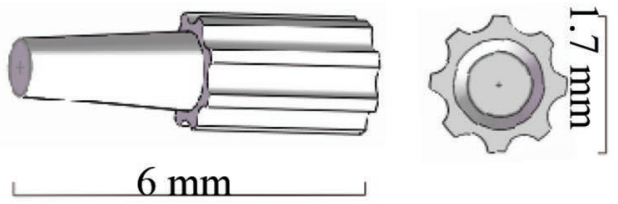

Figure 1. (a) Schematic of the effective and sensitive method of nucleic acid extraction using coaxial channel with magnetic silica beads; (b) schematic of the DNA extraction device; (c) schematic of the coaxial channel with the magnetic silica beads; (d) schematic of the aligner fabricated by the 3D printer; and (e) the coaxial channel. QuanPLEX, Each-Reach, Qingdao, Shandong, China. MSB = magnetic silica beads. Color version available online.

made of photosensitive resin and fabricated by a threedimensional printer (Objet24, Stratasys, Eden Prairie, $\mathrm{MN}$ ) to be concentric with the outer one. The inner capillary with the aligners was placed in the center of the outer one, and the coaxial channel was connected with a precise peristaltic pump (Type: T60-S2\&WX1014-A, flowrate: 0-24 mL/min, Longer Pump, Baoding, Hebei, China) for drawing the solutions.

Different from our previous design, we developed a new multiring magnetic field, which consisted of 2 repelling N35 neodymium magnets instead of the previous 1 . The new magnetic field was generated by placing 100 ring N40 neodymium magnets, purchased from a local store, with an outer diameter of $5.5 \mathrm{~mm}$, an inner diameter of $2.5 \mathrm{~mm}$, and a thickness of 1.0 $\mathrm{mm}$, in a mutual-repelling layout in the printed holder for magnetizing the iron ball chain. As this design had high-gradient magnetic fields close to both inner and outer walls of the coaxial channel, the magnetic beads could be captured against both walls with more uniform distribution; however, the beads were captured against only inner wall in the previous design. In addition, the magnetic silica beads with a mean diameter of $\sim 1 \mu \mathrm{m}$ for extracting the DNA of the E. coli O157:H7 cells were used as received without any modifications; however, in a previous study (Wang et al., 2017) the 
magnetic beads needed more complex antibody modification procedures.

\section{Extraction of the Target DNA}

The extraction of the target DNA from the lysed bacteria sample was conducted using this improved coaxial channel (see Figure 1a). Prior to the DNA extraction, the coaxial channel was blocked with $1 \%$ BSA for 45 min, followed by washing with deionized water at a flow rate of $0.5 \mathrm{~mL} / \mathrm{min}$ for $10 \mathrm{~min}$. First, $1 \mathrm{~mL}$ of the bacteria sample was mixed with the lysis buffer, including $300 \mu \mathrm{L}$ of guanidine salt and surfactant, $10 \mu \mathrm{L}$ of acryl carrier, and $5 \mu \mathrm{L}$ of protease $\mathrm{K}$, at $70^{\circ} \mathrm{C}$ for $10 \mathrm{~min}$ to release the DNA. The MSB with a concentration of 100 $\mathrm{mg} / \mathrm{mL}$ were then pumped to fill the coaxial channel at the absence of the magnetic field and distributed uniformly in the channel when the magnetic field was applied. After the lysed bacteria sample was pumped into the coaxial channel, the DNA was captured by the MSB through electrostatic interaction at the presence of chaotropic salts (Park et al., 2017), and $1 \mathrm{~mL}$ of absolute ethanol was pumped to remove the residual proteins. Finally, $100 \mu \mathrm{L}$ of the deionized water was pumped to fill the coaxial channel and the pump was automatically controlled by a microcontroller to work clockwise for $3 \mathrm{~s}$ and anti-clockwise for $3 \mathrm{~s}$ for $20 \mathrm{~min}$ for eluting the DNA from the MSB to obtain the purified and concentrated DNA templates.

\section{Amplification and Determination of the Extracted DNA}

The microfluidic PCR system, which consisted of the microfluidic chip developed in our laboratory for DNA amplification and the QuanPLEX platform from EachReach Biotech company (Qingdao, Shandong, China) for temperature control and fluorescence detection, was used to amplify and determine the amount of the extracted DNA. As shown in Figure 1 (b), a multichannel microfluidic chip with a length of $\sim 80 \mathrm{~mm}$, width of $\sim 30 \mathrm{~mm}$, and thickness of $\sim 5 \mathrm{~mm}$ was developed using the low-cost carving technique on the polycarbonate slice. After the mixture of PCR reaction was injected onto the chip, it was separated into 3 channels for parallel tests. The commercial primers and Taqman probes from Mabsky Biotech were used to determine the extracted DNA in the microfluidic chip with the QuanPLEX platform and compared with the Stepone real-time PCR platform from Applied Biosystems (Foster City, CA).

According to the protocol (http://en.mabsky.com/ cn/shiji/53.html; catalog no. SKY-8128) recommended by Mabsky, the total volume for both the microfluidic and traditional real-time PCR reaction was $25 \mu \mathrm{L}$, including $5 \mu \mathrm{L}$ of the DNA templates, $19.5 \mu \mathrm{L}$ of reaction mix, and $0.5 \mu \mathrm{L}$ of TaqDNA polymerase. However, this volume was used for 3 parallel tests in the microfluidic PCR system; therefore, the actual volume for each test was around $8 \mu \mathrm{L}$. The PCR reaction conditions were optimized by preprocess at $50^{\circ} \mathrm{C}$ for 2 min with uracil$\mathrm{N}$-glycosylase, predenaturation at $95^{\circ} \mathrm{C}$ for $3 \mathrm{~min}$, followed by 40 cycles of $95^{\circ} \mathrm{C}$ for $5 \mathrm{~s}$ and $55^{\circ} \mathrm{C}$ for $60 \mathrm{~s}$. Three cycle threshold $(\mathbf{C t})$ values of parallel PCR tests, which were automatically calculated by the software of the QuanPLEX platform, were obtained and averaged for the determination of the original copies of the target DNA. In addition, the purity and concentration of the target DNA templates were also measured using the NanoDrop 2000 Spectrophotometer (Thermo Fisher, Waltham, MA).

\section{Comparison of the DNA Extraction Methods}

The extraction of the target DNA using the manual magnetic silica bead-based method was conducted to compare with this proposed DNA extraction method. First, $1 \mathrm{~mL}$ of the bacteria sample was mixed with the same lysis buffer as described above at $70^{\circ} \mathrm{C}$ for $10 \mathrm{~min}$ to release the DNA. The same amount of MSB were then added and mixed at $15 \mathrm{rpm}$ for $3 \mathrm{~min}$ to capture the DNA, followed by conventional magnetic separation using a strong magnetic separator (SMS0204, Aibit, Jiangsu, China) for 2 min to remove the background, washing with $0.5 \mathrm{~mL}$ of absolute ethanol for $1 \mathrm{~min}$ twice to remove the residual proteins, and air-drying for 15 min to remove the residual ethanol. Finally, $100 \mu \mathrm{L}$ of the deionized water was used to elute the DNA from the MSB for 10 min and magnetic separation was used again to obtain the purified and concentrated DNA templates, which were determined using the Stepone real-time PCR.

\section{Detection of the Target Bacteria in Spiked Milk Samples}

As suggested in China's food safety national standards (http://file4.foodmate.net/foodvip/web/viewer.html ?file=../biaozhun/SNT0169-2010.pdf), the pasteurized milk from local supermarket was prepared by 10 -fold dilution with the sterile PBS before use (Li et al., 2016; $\mathrm{Yu}$ et al., 2017). One hundred microliters of each different concentration of the bacteria was mixed with $900 \mu \mathrm{L}$ of the prepared milk to prepare the spiked milk samples with the concentrations of $10^{1}$ to $10^{8} \mathrm{cfu} / \mathrm{mL}$. The DNA of the target bacteria was extracted by the 
proposed DNA extraction method using the improved coaxial channel to obtain the purified and concentrated DNA templates, which were amplified and determined using the microfluidic chip.

\section{RESULTS AND DISCUSSION}

\section{Optimization of the DNA Extraction Procedure}

The procedure for DNA extraction in our study mainly included capturing the MSB in the coaxial channel, binding the DNA with the MSB, washing the background with absolute ethanol, and eluting the DNA with deionized water. The time for background washing and DNA elution, and the flow rate of the solutions were crucial to the extraction efficiency. Thus, $1 \mathrm{~mL}$ of the pure E. coli $\mathrm{O} 157: \mathrm{H} 7$ cells at a concentration of $10^{7} \mathrm{cfu} / \mathrm{mL}$ were lysed with lysis buffer at $70^{\circ} \mathrm{C}$ for 10 min to obtain the DNA. The copies of DNA were determined by the proposed microfluidic PCR method. The ratio of the copies of the extracted DNA to those of the original DNA was defined as the DNA extraction efficiency.

As shown in Figure 2a, when the background washing time increased from 2 to 8 min, the DNA extraction efficiency increased from 57 to $95 \%$ and remained at the same level for $11 \mathrm{~min}$. This occurred because sufficient time was needed to wash the residual proteins and polysaccharides, which probably inhibited PCR reaction. Therefore, the optimal washing time of $8 \mathrm{~min}$ was used in our study.

As shown in Figure 2b, when the DNA elution time increased from 10 to $20 \mathrm{~min}$, the DNA extraction efficiency increased from 36\%to $97 \%$ and remained the same level for $25 \mathrm{~min}$. This indicated that almost all the DNA in the channel could be released from the MSB when deionized water (elution solution) was filled in the channel and then flowed back and forth for $20 \mathrm{~min}$. The reasons for a 20-min elution, primarily, were threefold. (1) The protocol from the manufacturer (http://www .huierbio.com/718.html) of the DNA extraction kit suggests the DNA elution at $65^{\circ} \mathrm{C}$ for $10 \mathrm{~min}$; however, in our study the DNA elution was conducted at room temperature and needed longer time. (2) One hundred microliters of deionized water was used for the DNA elution in our study, but the volume was not sufficient to cover the whole channel and deionized water had to move back and forth, resulting in longer time. (3) The longer time might allow more ethanol to evaporate from the elution buffer to reduce the effect on downstream PCR; thus, we used the optimal DNA elution time of 20 min.

As shown in Figure 2c, when the flow rate of the pump increased from 0.1 to $0.5 \mathrm{~mL} / \mathrm{min}$, the DNA extraction efficiency almost remained the same level of $\sim 96 \%$ and decreased to $45 \%$ for $1.0 \mathrm{~mL} / \mathrm{min}$. This might be because the weak binding between the DNA and the MSB resulted in partial loss of the DNA at the higher flow rate. Thus, we used the optimal flow rate of $0.5 \mathrm{~mL} / \mathrm{min}$.

\section{Effect of MSB on DNA Extraction}

The distribution and concentration of the MSB in the coaxial channel has a great effect on DNA extraction efficiency. The E. coli samples with concentrations of $10^{7} \mathrm{cfu} / \mathrm{mL}$ were lysed and used to investigate the effect of the MSB on DNA extraction. After a certain volume $(1-15 \mu \mathrm{L})$ of the MSB were captured in the coaxial channel, $1 \mathrm{~mL}$ of the lysed E. coli O157:H7 sample was first pumped into the coaxial channel at $0.5 \mathrm{~mL} / \mathrm{min}$. After adsorption for $2 \mathrm{~min}$ and washing for $8 \mathrm{~min}, 100$ $\mu \mathrm{L}$ of deionized water was used to elute the DNA for 20 min, which was detected by microfluidic PCR. As shown in Figure 2d, when the volume of MSB with a concentration of $100 \mathrm{mg} / \mathrm{mL}$ increased from 1 to $10 \mu \mathrm{L}$, the DNA extraction efficiency increased greatly from 14 to $96 \%$ and remained at the same level for $15 \mu \mathrm{L}$, indicating that $10 \mu \mathrm{L}$ of the magnetic silica beads were sufficient for capturing all the DNA in the channel. Therefore, we used the optimal MSB volume of $10 \mu \mathrm{L}$.

\section{Comparison of the Coaxial Channel with the Hollow Capillary for DNA Extraction}

The rapid and efficient extraction of the target DNA from the lysed sample in our study was mainly dependent on the use of the improved coaxial channel, as the target DNA could diffuse in the coaxial channel more rapidly, resulting in good binding with the uniformly distributed MSB. To verify this, the coaxial channel and the hollow capillary (i.e., the outer capillary without the inner one) were used to extract the DNA from the same $E$. coli sample with a concentration of $10^{8} \mathrm{cfu} /$ $\mathrm{mL}$ at optimal conditions.

As shown in Figure 3, the DNA extraction efficiency for the coaxial channel was $\sim 99 \%$; however, that for the hollow capillary was much lower, only $24 \%$. The high extraction efficiency for the coaxial channel could be attributed to one of three reasons. (1) The higher capture efficiency of the MSB in the coaxial channel, due to the presence of the multiring high-gradient magnetic field around the iron balls (see Figure 4a), may have resulted in a stronger magnetic force on the MSB. (2) The more uniform distribution of the MSB in the channel due to the line-up iron ball chain and the highgradient magnetic field at both inner and outer walls of the coaxial channel (see Figure 4b), avoiding the 
(a)

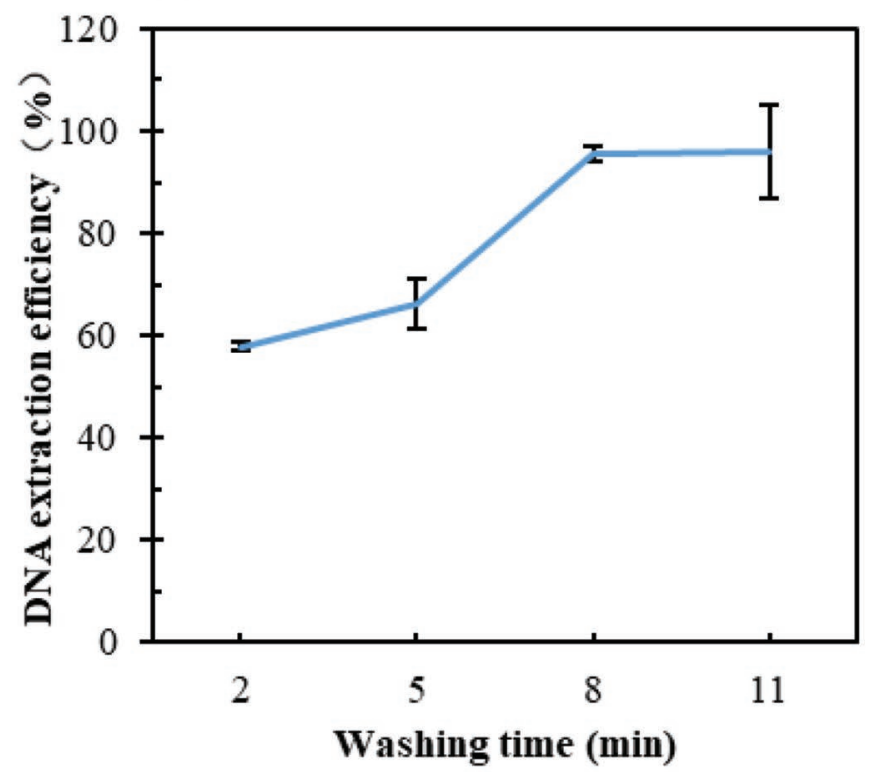

(c)

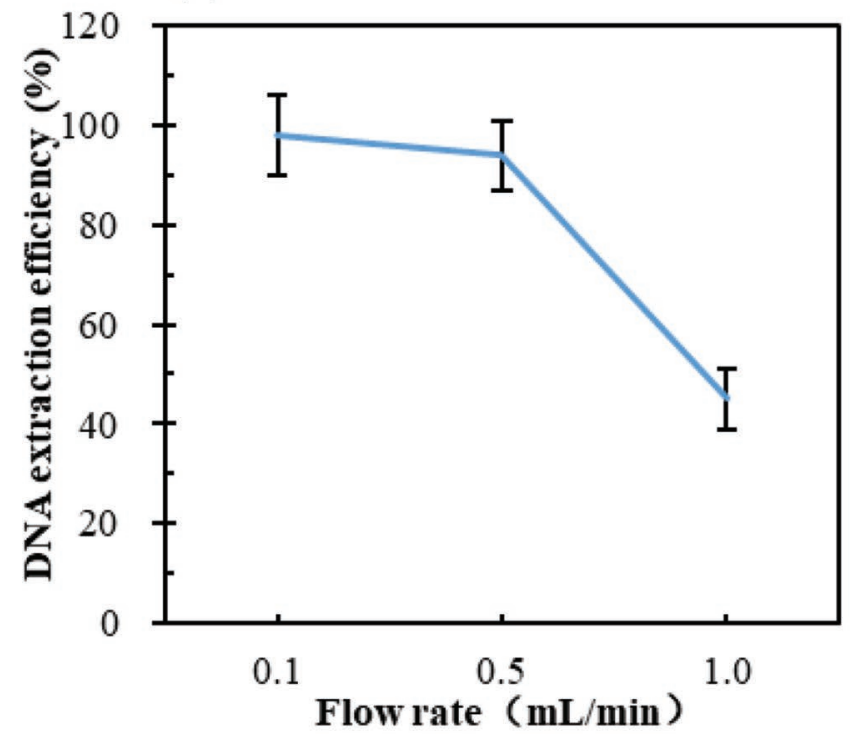

(b)

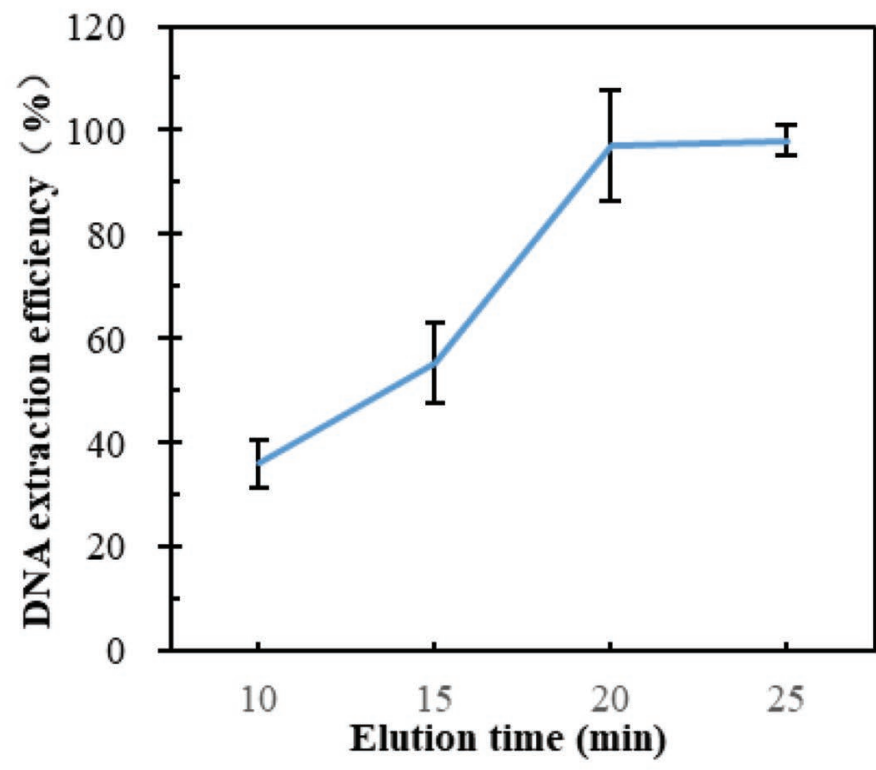

(d)

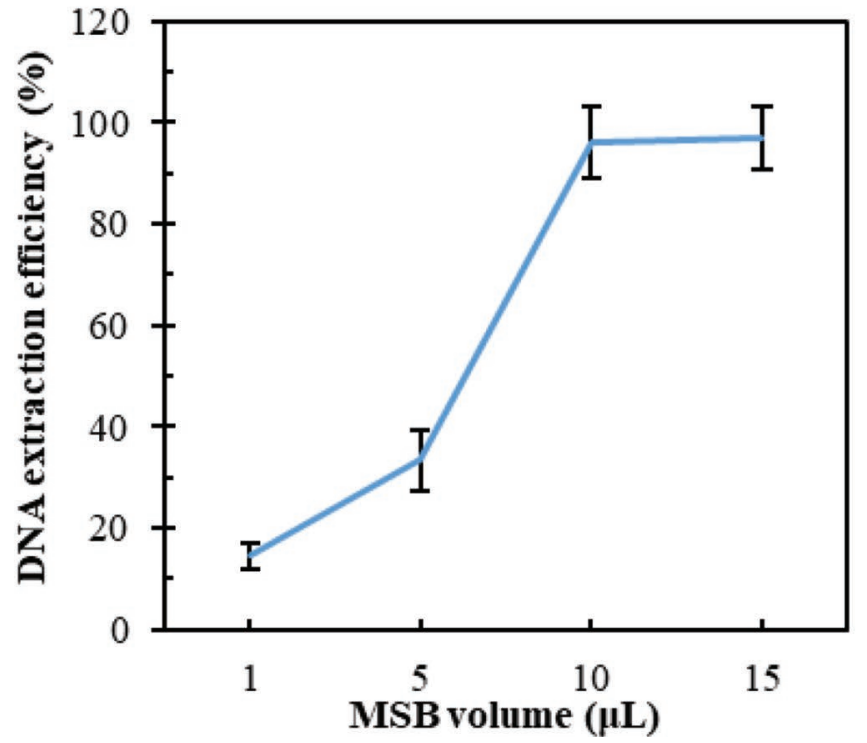

Figure 2. (a) The DNA extraction efficiency with different background washing time $(\mathrm{n}=3)$; (b) DNA extraction efficiency with different DNA elution time $(\mathrm{n}=3)$; (c) DNA extraction efficiency with different flow rates $(\mathrm{n}=3)$; and $(\mathrm{d})$ effect of the amount of magnetic silica beads on DNA extraction $(\mathrm{n}=3)$. The error bars on the graphs indicate SD. MSB = magnetic silica beads. Color version available online.

aggregation of the magnetic beads, may have resulted in higher reaction efficiency between the MSB and the target DNA. (3) Or, the smaller space in the channel for the DNA to flow through might have resulted in faster diffusion of the DNA into the whole channel and, thus, higher reaction efficiency between the MSB and the target DNA.

\section{Detection of the Target Bacteria in Pure Samples}

The detection of the pure E. coli $\mathrm{O} 157: \mathrm{H} 7$ samples at different concentrations ranging from $1.2 \times 10^{9}$ to $1.2 \times 10^{2} \mathrm{cfu} / \mathrm{mL}$ was conducted using our proposed bacteria detection method. Prior to testing, $1 \mathrm{~mL}$ of the pure E. coli $\mathrm{O} 157: \mathrm{H} 7$ sample was lysed at $70^{\circ} \mathrm{C}$ 
for $10 \mathrm{~min}$. Ten microliters of the MSB was first uniformly distributed in the channel. The lysed bacteria sample was then pumped into the coaxial channel at $0.5 \mathrm{~mL} / \mathrm{min}$ and the DNA was captured, followed by continuous-flow washing with the absolute ethanol for 8 min, pumping the air for $10 \mathrm{~min}$ to remove the residual ethanol, and eluting the DNA with $100 \mu \mathrm{L}$ of the deionized water. Furthermore, the DNA extraction of the $E$. coli $\mathrm{O} 157: \mathrm{H} 7$ samples at the same concentrations was also conducted using the manual magnetic silica beadbased method for comparison. All the extracted DNA templates were finally detected using the microfluidic PCR method.

As shown in Figure 5a, the microfluidic PCR method had a very close $\mathrm{Ct}$ value to the real-time PCR method when they were used to determine the same DNA templates, indicating that this PCR method could be used for DNA amplification and determination. As shown in Figure 5b and c, the DNA extraction efficiency using this proposed method is generally higher than that using the manual method, as the mean $\mathrm{Ct}$ value of the proposed method is $\sim 1.5$ less than that of the manual method, indicating the DNA templates extracted by this proposed method are $\sim 71.3 \%$ on average more than those by the manual method. Consequently, the PCR curves for the detection of $E$. coli $\mathrm{O} 157: \mathrm{H} 7$ at different concentrations, ranging from $1.2 \times 10^{9}$ to 1.2 $\times 10^{2} \mathrm{cfu} / \mathrm{mL}$, were shown in Figure $5 \mathrm{~d}$. A good linear relationship between the $\mathrm{Ct}$ value of $\mathrm{PCR}$ and the concentration (C) of E. coli $\mathrm{O} 157: \mathrm{H} 7$ was found and could be expressed as $\mathrm{Ct}=-3.02 \times \log (\mathrm{C})+46.65$ $\left(\mathrm{R}^{2}=0.98\right)$. When an unknown sample was tested, its

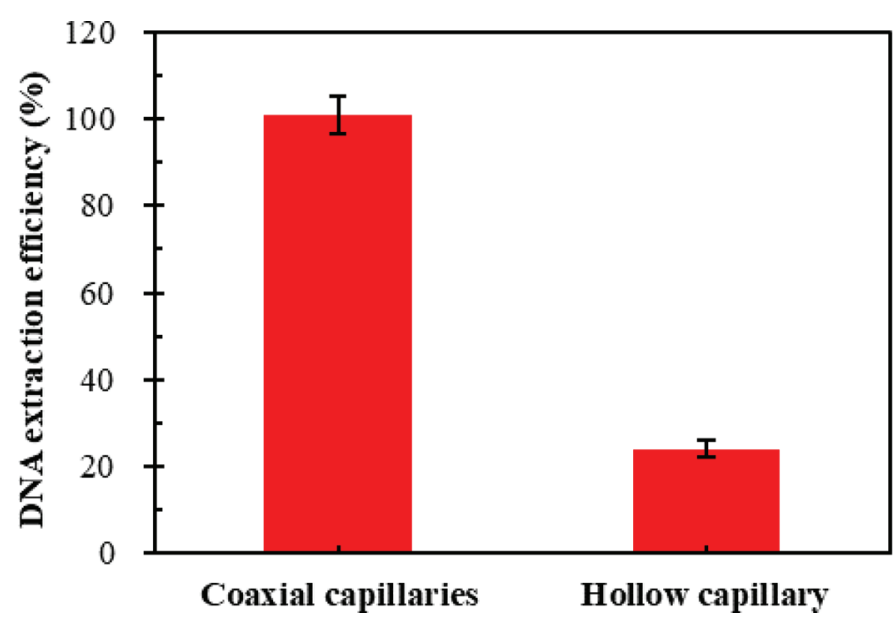

Figure 3. The comparison of the coaxial channel and the hollow capillary for DNA extraction $(\mathrm{n}=3)$. Color version available online.
Ct value would be obtained and used to calculate the concentration according to the equation.

The common method based on 3 times the signal-tonoise ratio for the determination of the limit of detection required the results of several negative controls; however, in our study the negative controls could not obtain valid $\mathrm{Ct}$ values, which were undetermined. We used the known concentrations (from $10^{9}$ to $10^{1} \mathrm{cfu} /$ $\mathrm{mL}$ ) of E. coli $\mathrm{O} 157: \mathrm{H} 7$, which were determined by the gold standard culture plating method, and found that the $\mathrm{Ct}$ values for concentrations from $10^{9}$ to $10^{2} \mathrm{cfu} /$ $\mathrm{mL}$ were valid and the value for concentrations of $10^{1}$ $\mathrm{cfu} / \mathrm{mL}$ was invalid. Therefore, the limit of detection of this proposed method was determined to be 1.2 $\times 10^{2} \mathrm{cfu} / \mathrm{mL}$. Moreover, the purity of the extracted DNA templates was measured using the NanoDrop 2000 Spectrophotometer, optical density (OD) 1 (A260/ $\mathrm{A} 280)=2.03, \mathrm{OD}_{2}(\mathrm{~A} 260 / \mathrm{A} 230)=0.51$, indicating that the DNA templates were pure. This proposed DNA extraction method had the potential to be realized in a microfluidic chip, and it would be easier to integrate with the microfluidic PCR than the conventional PCR or real-time PCR.

\section{Detection of the Target Bacteria in the Spiked Milk Samples}

To evaluate this proposed method for the detection of target bacteria in food samples, triplicate tests of pure E. coli O157:H7 cells at the concentrations ranging from $1.2 \times 10^{8}$ to $1.2 \times 10^{3} \mathrm{cfu} / \mathrm{mL}$ were spiked into pure pasteurized milk, which was purchased from local supermarket and 10-fold diluted with sterile PBS. The pure milk was used as negative control and the pure $E$. coli $\mathrm{O} 157: \mathrm{H} 7$ at the same concentrations were used for comparison. The $\mathrm{Ct}$ values of 3 negative controls were undetermined, indicating that no or very few E. coli O157:H7 cells were present in the milk. We calculated the recovery (R) of E. coli as

$$
\mathrm{R}=\mathrm{Ct}_{2} / \mathrm{Ct}_{1} \times 100 \%,
$$

where $\mathrm{Ct}_{1}$ and $\mathrm{Ct}_{2}$ are the $\mathrm{Ct}$ values of the $E$. coli O157:H7 spiked milk samples and the pure E. coli O157:H7 samples, respectively. The recoveries for different concentrations $\left(1.2 \times 10^{8}\right.$ to $\left.1.2 \times 10^{3} \mathrm{cfu} / \mathrm{mL}\right)$ of $E$. coli in the spiked milk samples ranged from 97.4 to $100.6 \%$, indicating that this proposed bacteria detection method was applicable for the detection of the target bacteria in the milk samples. 
Detection of the Target Bacteria in Large Volumes of Bacterial Sample

The purpose of our study was to develop an ultrasensitive bacteria detection method using the coaxial channel with the MSB to continuous-flow extract small amounts of target DNA from a large volume of sample for increasing the sensitivity of PCR detection. Therefore, E. coli O157:H7 cells at a concentration of $1.2 \times$ $10^{2} \mathrm{cfu} / \mathrm{mL}$ were 10 times diluted by PBS to prepare (a)

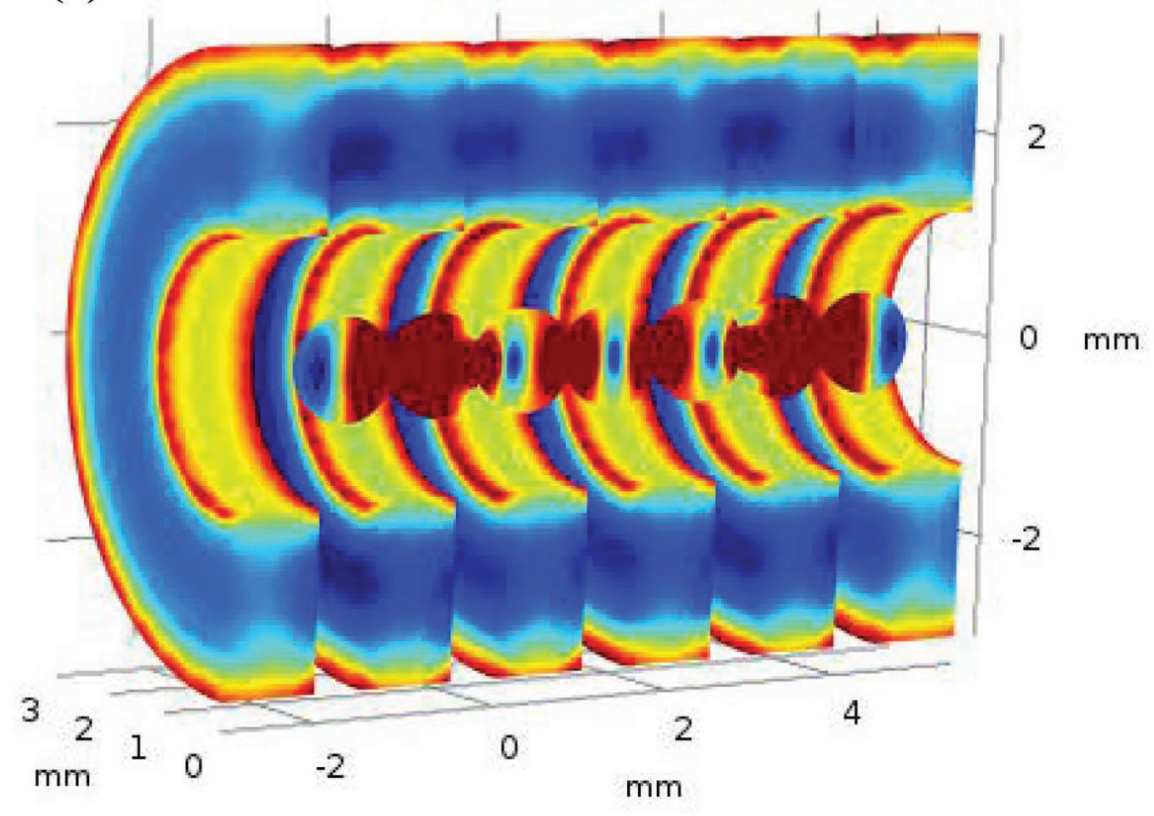

T

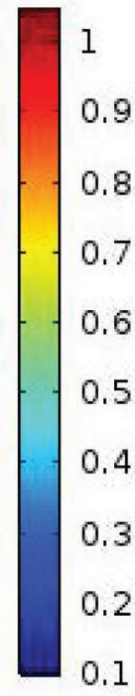

(b)

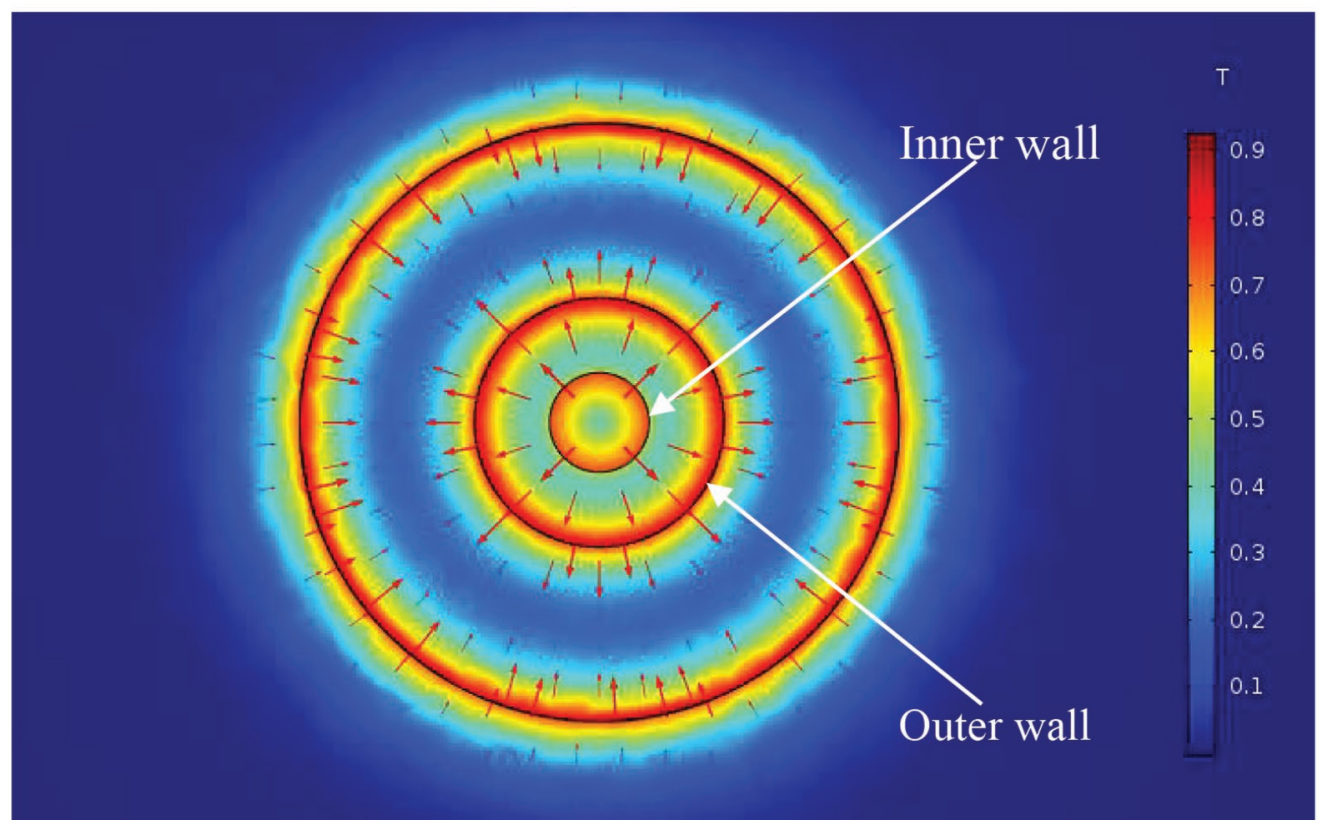

Figure 4. (a) Simulation of the magnetic field distribution in the coaxial channel and (b) cross-section distribution of the magnetic field. Color version available online. 
ZHANG ET AL.
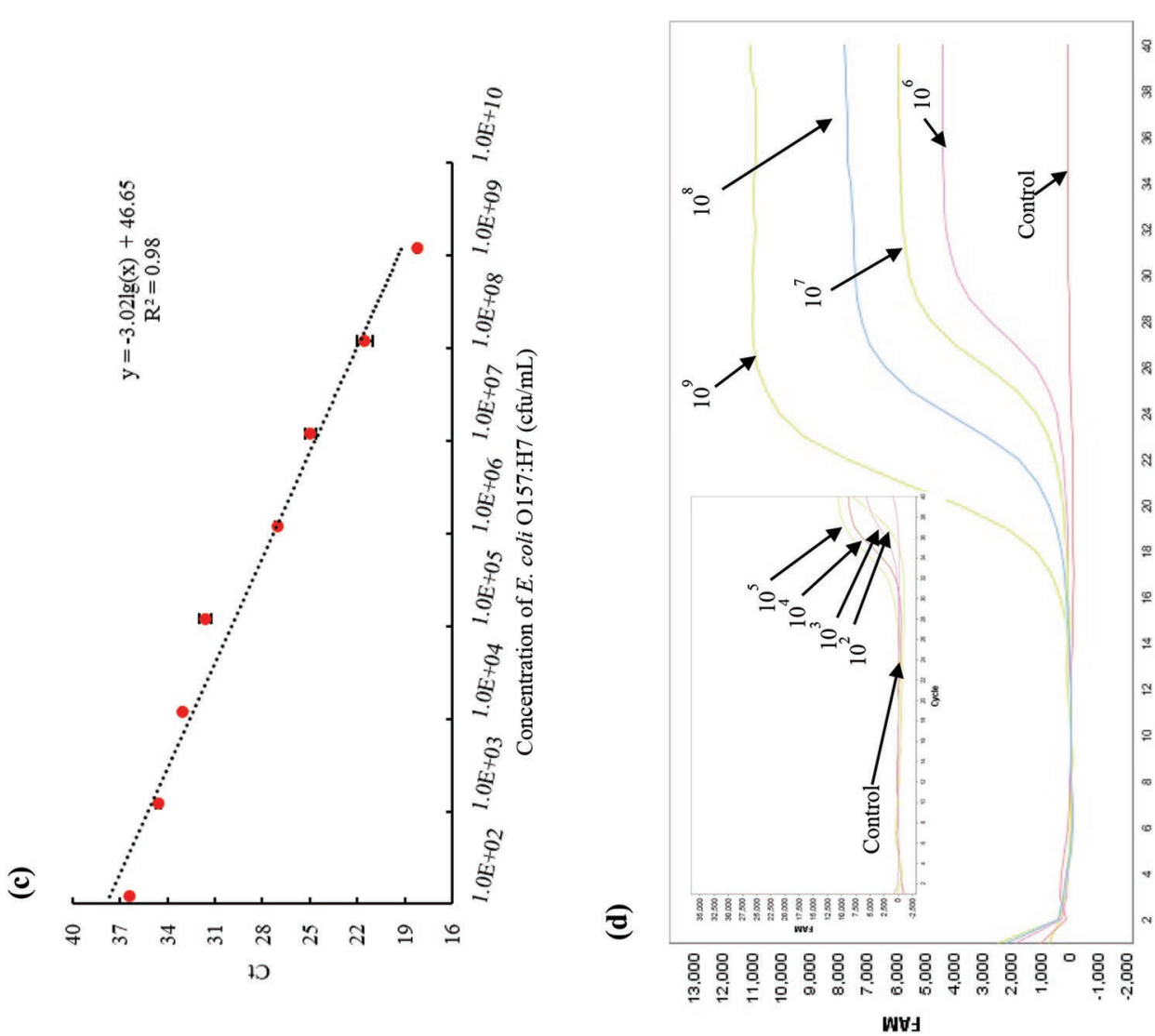

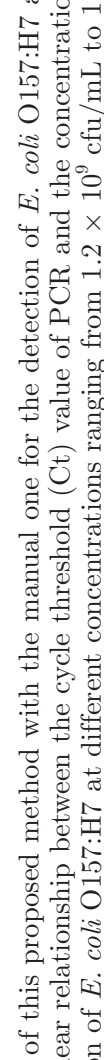

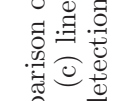
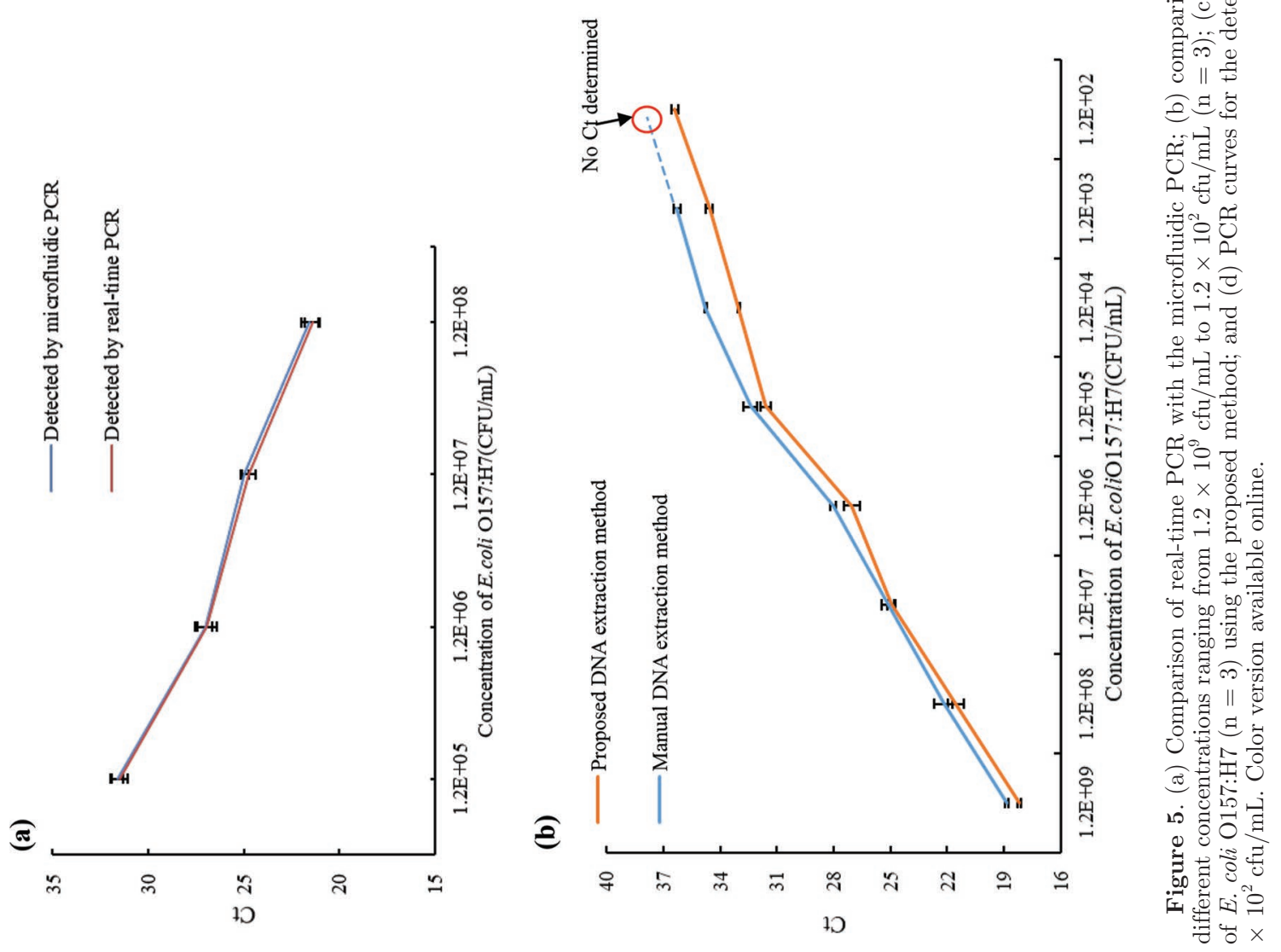

Journal of Dairy Science Vol. 101 No. 11, 2018 
a larger volume $(10 \mathrm{~mL})$ of target bacteria at lower concentration $\left(1.2 \times 10^{1} \mathrm{cfu} / \mathrm{mL}\right)$. One milliliter of the original concentration $\left(1.2 \times 10^{2} \mathrm{cfu} / \mathrm{mL}\right)$ of the target bacteria and $10 \mathrm{~mL}$ of the diluted concentration $(1.2$ $\times 10^{1} \mathrm{cfu} / \mathrm{mL}$ ) of the target bacteria, which contained the same amount of the target bacteria (120 bacterial cells), were both processed using this proposed method under the optimal conditions, respectively. The mean Ct value for $3 E$. coli O157:H7 samples at a concentration of $1.2 \times 10^{1} \mathrm{cfu} / \mathrm{mL}$ in $10 \mathrm{~mL}$ of PBS was 36.5 , and almost consistent with that for 3 samples at the concentration $1.2 \times 10^{2} \mathrm{cfu} / \mathrm{mL}$ in $1 \mathrm{~mL}$ of PBS (36.4). This result demonstrated that the proposed DNA-extraction method could obtain $\sim 10$ times the target DNA templates using the larger volume $(10 \mathrm{~mL})$ instead of the conventional volume $(1 \mathrm{~mL})$, indicating that it could improve sensitivity of the PCR method $\sim 10$ times. Thus, the combination of the proposed DNA-extraction method and the microfluidic PCR method was able to detect E. coli $\mathrm{O} 157: \mathrm{H} 7$ as low as $1.2 \times 10^{1} \mathrm{cfu} / \mathrm{mL}$.

\section{CONCLUSIONS}

In this study, a rapid and sensitive method for detection of E. coli O157:H7 using the improved coaxial channel-based DNA extraction and the microfluidic PCR was developed and evaluated. This proposed method was able to detect $E$. coli $\mathrm{O} 157: \mathrm{H} 7$ as low as $1.2 \times 10^{1} \mathrm{cfu} / \mathrm{mL}$ when a large volume $(10 \mathrm{~mL})$ of bacteria sample was used. This proposed DNA-extraction method has the potential to extract more target DNA templates from a larger volume of sample and elute the DNA from the MSB with a smaller volume of deionized water to further increase the sensitivity.

\section{ACKNOWLEDGMENTS}

This study was supported by the National Key Research and Development of China (2016YFD0500903) and Science and Technology Support Plan of Hebei Province of China (No. 16272404D).

\section{REFERENCES}

Abolmaaty, A., H. Chen, and M. Faghri. 2013. Direct detection of $E$. coli $\mathrm{O} 157: \mathrm{H} 7$ in ground beef via anti-digoxigenin immuno-PCR assay. World Appl. Sci. J. 14:591-598.

Ali, M. E., M. A. Razzak, and S. B. A. Hamid. 2014. Multiplex PCR in species authentication: Probability and prospects - A review. Food Anal. Methods 7:1933-1949.

Bai, Y., M. Song, Y. Cui, C. Shi, D. Wang, G. C. Paoli, and X. Shi. 2013. A rapid method for the detection of foodborne pathogens by extraction of a trace amount of DNA from raw milk based on amino-modified silica-coated magnetic nanoparticles and polymerase chain reaction. Anal. Chim. Acta 787:93-101.

Berry, S. M., E. T. Alarid, and D. J. Beebe. 2011. One-step purification of nucleic acid for gene expression analysis via Immis- cible Filtration Assisted by Surface Tension (IFAST). Lab Chip 11:1747-1753.

Bian, X., F. Jing, G. Li, X. Fan, C. Jia, H. Zhou, Q. Jin, and J. Zhao. 2015. A microfluidic droplet digital PCR for simultaneous detection of pathogenic Escherichia coli O157 and Listeria monocytogenes. Biosens. Bioelectron. 74:770-777.

Bordelon, H., N. M. Adams, A. S. Klemm, P. K. Russ, J. V. Williams, H. K. Talbot, D. W. Wright, and F. R. Haselton. 2011. Development of a low-resource RNA extraction cassette based on surface tension valves. ACS Appl. Mater. Interfaces 3:2161-2168.

Bordelon, H., P. K. Russ, D. W. Wright, and F. R. Haselton. 2013. A magnetic bead-based method for concentrating DNA from human urine for downstream detection. PLoS One 8:e68369.

Casey, A., and O. McAuliffe. 2014. Extraction and analysis of plasmid DNA from Listeria monocytogenes. Methods Mol. Biol. 1157:181186.

Chandrashekhar, K. M., S. Isloor, B. H. Veeresh, R. Hegde, D. Rathnamma, S. Murag, B. M. Veeregowda, H. A. Upendra, and N. R. Hegde. 2015. Limit of detection of genomic DNA by conventional PCR for estimating the load of Staphylococcus aureus and Escherichia coli associated with bovine mastitis. Folia Microbiol. (Praha) 60:465-472.

Chen, J., L. Zhang, G. C. Paoli, C. Shi, S. I. Tu, and X. Shi. 2010. A real-time PCR method for the detection of Salmonella enterica from food using a target sequence identified by comparative genomic analysis. Int. J. Food Microbiol. 137:168-174.

Gan, W., Y. Gu, J. Han, C. X. Li, J. Sun, and P. Liu. 2017. Chitosanmodified filter paper for nucleic acid extraction and "in situ PCR" on a thermoplastic microchip. Anal. Chem. 89:3568-3575.

Ganesh, I., B. M. Tran, Y. Kim, J. Kim, H. Cheng, N. Y. Lee, and S. Park. 2016. An integrated microfluidic PCR system with immunomagnetic nanoparticles for the detection of bacterial pathogens. Biomed. Microdevices 18:116.

Huang, F., H. Zhang, L. Wang, W. Lai, and J. Lin. 2018. A sensitive biosensor using double-layer capillary based immunomagnetic separation and invertase-nanocluster based signal amplification for rapid detection of foodborne pathogen. Biosens. Bioelectron. 100:583-590.

Jie, L., W. Hao, Z. Shuai, D. D. Zhang, M. D. Lai, and Y. M. Zhu. 2012. (Optimization of genomic DNA extraction with magnetic bead- based semi-automatic system). Journal of Zhejiang University $41: 320$.

Kérouanton, A., M. Marault, L. Petit, J. Grout, T. T. Dao, and A. Brisabois. 2010. Evaluation of a multiplex PCR assay as an alternative method for Listeria monocytogenes serotyping. J. Microbiol. Methods 80:134-137.

Lee, S. H., H. J. Lee, S. J. Kim, H. M. Lee, H. Kang, and Y. P. Kim. 2010. Identification of airborne bacterial and fungal community structures in an urban area by T-RFLP analysis and quantitative real-time PCR. Sci. Total Environ. 408:1349-1357.

Levison, P. R., S. E. Badger, J. Dennis, P. Hathi, M. J. Davies, I. J. Bruce, and D. Schimkat. 1998. Recent developments of magnetic beads for use in nucleic acid purification. J. Chromatogr. A 816:107-111.

Li, F., G. Xie, B. Zhou, P. Yu, S. Yu, Z. P. Aguilar, H. Wei, and H. Xu. 2016. Rapid and simultaneous detection of viable Cronobacter sakazakii, Staphylococcus aureus, and Bacillus cereus, in infant food products by PMA-mPCR assay with internal amplification control. Lebensm. Wiss. Technol. 74:176-182.

Mauk, M. G., C. Liu, J. Song, and H. H. Bau. 2015. Integrated microfluidic nucleic acid isolation, isothermal amplification, and amplicon quantification. Microarrays (Basel) 4:474-489.

Pandey, A., Y. Gurbuz, V. Ozguz, J. H. Niazi, and A. Qureshi. 2017. Graphene-interfaced electrical biosensor for label-free and sensitive detection of foodborne pathogenic E. coli O157:H7. Biosens. Bioelectron. 91:225-231.

Park, B. H., S. J. Oh, J. H. Jung, G. Choi, J. H. Seo, D. H. Kim, E. Y. Lee, and T. S. Seo. 2017. An integrated rotary microfluidic system with DNA extraction, loop-mediated isothermal amplification, and lateral flow strip based detection for point-of-care pathogen diagnostics. Biosens. Bioelectron. 91:334-340. 
Ryazantsev, D. Y., D. V. Voronina, and S. K. Zavriev. 2016. Immuno-PCR: Achievements and perspectives. Biochemistry (Mosc.) $81: 1754-1770$

Sheng, J., T. Tao, X. Zhu, X. Bie, F. Lv, H. Zhao, and Z. Lu. 2018. A multiplex PCR detection method for milk based on novel primers specific for Listeria monocytogenes 1/2a serotype. Food Control $86: 183-190$.

Stefanova, P., M. Taseva, T. Georgieva, V. Gotcheva, and A. Angelov 2014. A Modified CTAB method for DNA extraction from soybean and meat products. Biotechnol. Biotechnol. Equip. 27:3803-3810.

Sur, K., S. M. McFall, E. T. Yeh, S. R. Jangam, M. A. Hayden, S D. Stroupe, and D. M. Kelso. 2010. Immiscible phase nucleic acid purification eliminates PCR inhibitors with a single pass of paramagnetic particles through a hydrophobic liquid. J. Mol. Diagn. $12: 620-628$.
Wang, L., F. Huang, G. Cai, L. Yao, H. Zhang, and J. Lin. 2017 An electrochemical aptasensor using coaxial capillary with magnetic nanoparticle, urease catalysis and pcb electrode for rapid and sensitive detection of Escherichia coli O157:H7. Nanotheranostics 1:403.

Yalçinkaya, B., E. Yumbul, E. Mozioglu, and M. Akgoz. 2017. Comparison of DNA extraction methods for meat analysis. Food Chem. 221:1253-1257.

Yu, S., L. Yan, X. Wu, F. Li, D. Wang, and H. Xu. 2017. Multiplex PCR coupled with propidium monoazide for the detection of viable Cronobacter sakazakii, Bacillus cereus, and Salmonella spp. in milk and milk products. J. Dairy Sci. 100:7874.

Zhang, Y., and H. R. Jiang. 2016. A review on continuous-flow microfluidic PCR in droplets: Advances, challenges and future. Anal. Chim. Acta 914:7-16. 